\title{
Neurodevelopmental marker for limbic maldevelopment in antisocial personality disorder and psychopathy
}

\author{
Adrian Raine, Lydia Lee, Yaling Yang and Patrick Colletti
}

\section{Background}

Antisocial personality disorder and psychopathy have been hypothesised to have a neurodevelopmental basis, but this proposition has not been formally tested.

\begin{abstract}
Aims
This study tests the hypothesis that individuals with cavum septum pellucidum (CSP), a marker of limbic neural maldevelopment, will show higher levels of psychopathy and antisocial personality.

\section{Method}

Cavum septum pellucidum was assessed using anatomical magnetic resonance imaging in a community sample. Those with CSP $(n=19)$ were compared with those lacking CSP $(n=68)$ on antisocial personality, psychopathy and criminal offending.
\end{abstract}

\section{Results}

Those with CSP had significantly higher levels of antisocial personality, psychopathy, arrests and convictions compared with controls. The pervasiveness of this association was indicated by the fact that those lacking a diagnosis of antisocial personality disorder, but who were charged or convicted for an offence, had a more extensive CSP than non-antisocial controls. Results could not be attributed to prior trauma exposure, head injury, demographic factors or comorbid psychiatric conditions.

\section{Conclusions}

Our findings appear to be the first to provide evidence for a neurodevelopmental brain abnormality in those with antisocial personality disorder and psychopathy, and support the hypothesis that early maldevelopment of limbic and septal structures predisposes to the spectrum of antisocial behaviours.

\section{Declaration of interest}

None.
Violence is increasingly being viewed by the Department of Health and Human Services in the USA and other international agencies as a global public health problem. ${ }^{1,2}$ Although a neurodevelopmental basis to violent and antisocial behaviour has long been hypothesised, ${ }^{3,4}$ there has been no prior investigation of a structural brain abnormality reflective of early neural maldevelopment in any antisocial population. Although abnormal structure/function in multiple limbic and paralimbic structures, including the amygdala ${ }^{5-8}$ hippocampus ${ }^{8-10}$ thalamus, ${ }^{8}$ hypothalamus, ${ }^{11}$ anterior cingulate, ${ }^{5}$ posterior cingulate, ${ }^{12}$ insula ${ }^{7,13}$ and orbitofrontal cortex, ${ }^{6,13,14}$ has been reported in adult antisocial, aggressive and psychopathic individuals, brain impairments could conceivably be a consequence of a violent lifestyle rather than a cause, and consequently it is difficult to infer causality from cross-sectional studies. Neurological research on people with head injury does, however, suggest that brain impairment may be of aetiological or pathophysiological significance with respect to psychopathy, ${ }^{15-17}$ although genetic factors cannot be ruled out. Furthermore, initial imaging findings on structural and functional brain abnormalities in child and adolescent populations characterised by antisocial behaviour and callous-unemotional traits is suggestive of a possible neurodevelopmental basis to antisocial and psychopathic behaviour. ${ }^{6,18-23}$

Cavum septum pellucidum (CSP - referred to historically as cavum septi pellucidi) is a marker for fetal neural maldevelopment. The septum pellucidum is one component of the septum and consists of a deep, midline, limbic structure made up of two translucent leaves of glia separating the lateral ventricles, forming part of the septohippocampal system. It consists predominantly of ependymal glia and fibre tracts beneath the genu and rostrum of the corpus callosum on the medial side of the frontal lobe. ${ }^{24}$
Another component of the septum (the septum verum) contains the septal nuclei, lying more ventrally in the paraterminal gyrus. During fetal development at approximately the twelfth week of gestation, a space forms between the two laminae - the CSP closure of which begins at approximately the twentieth week of gestation and ends shortly after birth (3-6 months postnatally). ${ }^{25}$ Fusion of the CSP is attributed to rapid development of the alvei of the hippocampus, amygdala, septal nuclei, fornix, corpus callosum and other midline structures. ${ }^{26,27}$ Lack of such limbic development interrupts this posterior-to-anterior fusion, resulting in preservation of the CSP into adulthood.

There are individual differences in the degree of this neurodevelopmental abnormality; whereas some have complete closure of the cavum, others present with a small degree $(>6 \mathrm{~mm}$ in the coronal plane) of incomplete closure. ${ }^{26,27}$ The cause of the maldevelopment of midline limbic structures that results in CSP is largely unknown, although it is thought that prenatal alcohol exposure plays a significant teratogenic role. ${ }^{28}$

To test the neurodevelopmental hypothesis of antisocial personality disorder and psychopathy, we examined the presence of CSP in antisocial and psychopathic individuals using anatomical magnetic resonance imaging (MRI) in a community sample at risk for antisocial personality disorder and psychopathy. If antisocial personality disorder and psychopathic behaviour are partly a product of disrupted limbic neurodevelopment in the prenatal and early postnatal months, those with a CSP would be hypothesised to show more antisocial, psychopathic and criminal behaviour. The pervasiveness of the hypothesised relationship was further tested by assessing whether individuals lacking antisocial personality disorder, but who nevertheless show some degree of criminal activity, also show more evidence of CSP than non-antisocial controls. 


\section{Method}

\section{Participants}

Eighty-seven participants (75 male, 12 female) were recruited from five temporary employment agencies. ${ }^{29}$ Exclusion criteria were: age under 21 or over 46, non-fluency in English, history of epilepsy, claustrophobia, pacemaker, ostensible neurological abnormality and metal implants. Ethnic representation was as follows: White (51\%), Asian (6\%), Hispanic (13\%), African American (29\%), and other (1\%). Written informed consent was obtained, and the study was approved by an institutional review board. This community recruitment strategy is novel, but has the advantage that it samples individuals at high socioeconomic risk, with an eightfold increase in the yield of those with psychopathy/antisocial personality. ${ }^{29}$ To maximise confidentiality and minimise denial of self-report crime, a certificate of confidentiality was obtained from the Secretary of Health and Human Service under section 303(a) of the Public Health Act 42.

\section{Antisocial personality disorder and criminal offending}

Diagnoses of antisocial personality disorder and psychopathy were made by two PhD-level research assistants who had undergone a standardised training and quality assurance programme for diagnostic assessment. ${ }^{30}$ Antisocial personality disorder was assessed using the DSM-IV criteria $^{31}$ and the Structured Clinical Interview for DSM-IV Axis II Personality Disorders (SCID-II). ${ }^{32}$ Eighteen participants fulfilled antisocial personality disorder criteria (17 male, 1 female). Criminal offending was assessed for all participants from criminal history record searches provided by the Bureau of Criminal Statistics, Department of Justice, yielding information on number of both police arrests (33 male, 4 female) and court convictions (26 male, 3 female).

\section{Psychopathic personality}

Psychopathy was assessed using the Psychopathy ChecklistRevised (PCL-R). ${ }^{33}$ A total score (range 0-40) and two subfactors (interpersonal/affective and social deviance) were derived. ${ }^{33}$ Internal reliability (Cronbach's alpha) was 0.90 . Assessments were supplemented by five additional sources of collateral data (see Raine et $a l^{10}$ for full details). Consistent with our prior work in community samples ${ }^{10,29,34,35}$ those with a PCL-R score of 23 or more were designated as psychopathic ( 30 male, 2 female).

\section{Cognitive, trauma, psychiatric and demographic assessments}

Four subtests (vocabulary, arithmetic, block design and digit symbol) of the Wechsler Adult Intelligence Scale - Revised (WAIS-R) $^{36}$ were used to estimate IQ. In total $20.4 \%$ of the sample had been exposed to life-threatening traumatic events. Because only one participant met full DSM-IV diagnostic criteria for post-traumatic stress disorder (PTSD), degree of traumatic stress was assessed by summing scores on the five PTSD criteria of DSM-IV. Similarly, a dimensional measure of antisocial personality disorder was created by summing SCID scores on individual antisocial personality disorder symptoms. Potential psychiatric confounds (alcohol misuse/dependence, substance misuse/dependence, schizophrenia-spectrum disorders, psychosis, bipolar disorder, depression) were assessed using the SCID-I and II. Head injury was defined as the number of times knocked unconscious. ${ }^{29}$ Social class was measured using the Hollingshead classification system. ${ }^{37}$ Group scores and comparisons on psychiatric, cognitive and demographic measures are given in Table 1.

\section{MRI}

\section{Acquisition}

Structural MRIs were conducted on a Philips S15/ACS scanner (Selton, Connecticut) with a 1.5 tesla magnet. Following an initial alignment sequence of one midsaggital and four parasagittal scans (spin-echo $T_{1}$-weighted image acquisition, repetition time (TR) $600 \mathrm{~ms}$, echo time (TE) $20 \mathrm{~ms}$ ) to identify the anterior commissure-posterior commissure (AC-PC) plane, 128 3-D $T_{1}$-weighted gradient-echo coronal images ( $\mathrm{TR}=34 \mathrm{~ms}$, $\mathrm{TE}=12.4 \mathrm{~ms}$, flip angle $35^{\circ}, 1.7 \mathrm{~mm}$ slices, $256 \times 256$ matrix, field of view (FOV) $23 \mathrm{~cm}$ ) were taken orthogonal to the AC-PC line.

\section{CSP assessment}

Image preprocessing was conducted using individual executable programs in a processing tree using the LONI Pipeline Processing

\begin{tabular}{|c|c|c|c|c|c|c|c|c|c|c|}
\hline & \multicolumn{4}{|c|}{ Control group $(n=69)$} & \multicolumn{4}{|c|}{ Antisocial personality disorder group $(n=18)$} & \multirow[b]{2}{*}{ Statistic } & \multirow[b]{2}{*}{$P$} \\
\hline & $\%(n)$ & Mean & s.d. & Range & $\%(n)$ & Mean & s.d. & Range & & \\
\hline \multicolumn{11}{|l|}{ Demographics } \\
\hline Age, years & & 31.23 & 6.83 & $21-46$ & & 32.72 & 6.54 & $24-44$ & $t=0.82$ & 0.41 \\
\hline Social class & & 35.00 & 10.84 & $17-58$ & & 33.83 & 7.64 & $16-43$ & $t=1.0$ & 0.32 \\
\hline Ethnicity, White & $56.17(36)$ & & & & $33.33(6)$ & & & & $\chi^{2}=2.95$ & 0.11 \\
\hline Gender, male & $84.1(58)$ & & & & $94.4(17)$ & & & & $\chi^{2}=1.52$ & 0.22 \\
\hline \multicolumn{11}{|l|}{ Cognitive } \\
\hline Total IQ & & 99.49 & 15.91 & $66-134$ & & 98.44 & 12.12 & $78-118$ & $t=0.8$ & 0.41 \\
\hline \multicolumn{11}{|l|}{ Trauma } \\
\hline Number of head injuries & & 2.22 & 4.47 & $0-25$ & & 2.23 & 3.01 & 0-12 & $\chi^{2}=0.6$ & 0.73 \\
\hline Traumatic stress & & 2.29 & 5.29 & $0-28$ & & 2.72 & 5.89 & $0-20$ & $t=-0.27$ & 0.78 \\
\hline \multicolumn{11}{|l|}{ Antisocial } \\
\hline \multicolumn{11}{|l|}{ Psychopathy Checklist-Revised } \\
\hline Total scores & & 15.88 & 6.43 & $5-30$ & & 28.65 & 6.12 & $21-40$ & $t=14.8$ & 0.0001 \\
\hline Factor 1 & & 5.32 & 3.52 & $0-16$ & & 10.05 & 3.56 & $4-16$ & $t=8.4$ & 0.0001 \\
\hline Factor 2 & & 7.15 & 2.97 & $0-15$ & & 13.70 & 2.91 & 9-18 & $t=9.2$ & 0.0001 \\
\hline Antisocial personality disorder score & & 4.31 & 2.64 & $0-10$ & & 10.50 & 2.28 & $6-14$ & $t=12.7$ & 0.0001 \\
\hline Charges & & 2.86 & 10.03 & $0-53$ & & 6.94 & 6.52 & $0-20$ & $t=-1.61$ & 0.11 \\
\hline Convictions & & 0.94 & 3.58 & $0-22$ & & 2.44 & 2.50 & $0-9$ & $t=-1.65$ & 0.10 \\
\hline
\end{tabular}


Environment. ${ }^{38}$ Images were first reformatted as $1.0 \mathrm{~mm}$ slices to increase resolution for visual analysis. Anatomical boundaries for CSP were as follows: the genu of the corpus callosum defined the anterior boundary, the body of the corpus callosum defined the superior boundary, the rostrum of the corpus callosum and fornix defined the inferior boundary, and the junction of the splenium of the corpus callosum with the crus of the fornix defined the posterior boundary. The number of coronal $1 \mathrm{~mm}$ slices on which the CSP was present was recorded. Following the convention of other studies ${ }^{28,39,40}$ presence of CSP was defined as a CSP of $6 \mathrm{~mm}$ or greater length $(n=19 ; 14$ male, 5 female). Scoring was performed in the anterior-to-posterior direction in the coronal view, using a simultaneous sagittal view to ensure that consistent anatomical boundaries were maintained. Scoring was conducted masked to all other participant data. Twenty-five participants were randomly selected and scored by a second rater masked to group membership and the other rater's assessment; interrater reliability of length of CSP was high $(r=0.98)$. A coronal illustration of CSP is provided in Fig.1.

\section{Statistical analyses}

All analyses were conducted using SPSS 10 for Windows. A 2 (CSP present/absent $) \times 2($ male/female $)$ univariate analyses of variance design was conduced with antisocial measures as dependent variables, in addition to multivariate analyses for subfactors of psychopathy. In each analysis on the antisocial construct in question (e.g. antisocial personality disorder, psychopathy) those with, for example, antisocial personality disorder were compared with all others in the sample who did not fulfil criteria for antisocial personality disorder. All tests of significance are two-tailed. Effect sizes were calculated using $\eta^{2}$ (\% variance accounted for). Factor analysis using an oblimin oblique rotation was used to derived subfactors of antisocial personality disorder to assess whether CSP was more associated with aggressive/life-course features.

\section{Results}

\section{Antisocial personality disorder}

A main effect of CSP grouping indicated higher scores on antisocial personality disorder (mean 6.20) in the CSP group compared with controls (mean 5.29) $(F(1,83)=5.00, P=0.028$, $\eta^{2}=0.057$, Fig. 2). Males had higher antisocial personality disorder scores (mean 5.29) than females (mean 0.50) $\left(F(1,83)=8.85, P=0.004, \eta^{2}=0.096\right)$, but there was no cavum $\times$ gender interaction $(P=0.11)$.

\section{Subfeatures of antisocial personality disorder}

Two subcomponents of antisocial personality disorder were derived using factor analysis. Significant $(>0.30)$ loadings on the aggressive/life-course factor (coefficient $\alpha=0.71$ ) consisted of irritability/aggressiveness (0.83), reckless disregard for self/ others (0.70), child/adolescent conduct disorder (0.69), failure to conform to social norms (0.64) and lack of remorse (0.33). Loadings on the deceptive-irresponsible factor (coefficient $\alpha=0.67$ ) were deceitfulness (0.89), consistent irresponsibility (0.77), impulsivity $(0.60)$ and lack of remorse $(0.31)$. The two factors intercorrelated $0.46(P<0.001)$. The regression method was used to estimate factor scores for each factor.

Presence of a CSP was more related to the aggressive/lifecourse component of antisocial personality disorder than to deceptive-irresponsible features (Fig. 3). A main effect of CSP grouping indicated higher aggression scores in the CSP group (a)

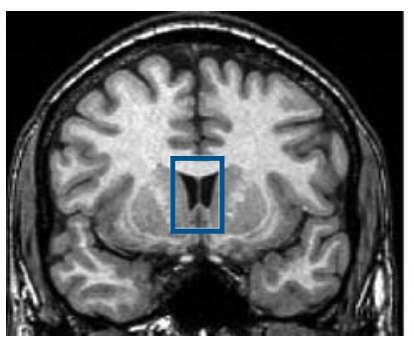

(b)

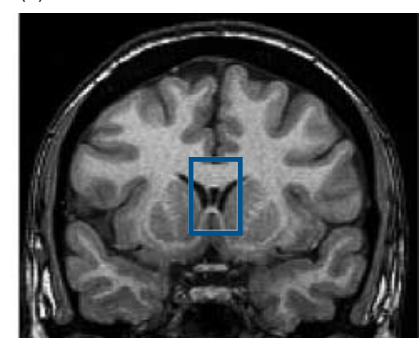

Fig. 1 lllustration of normal septum pellucidum (thin membrane separating the lateral ventricles) in a non-antisocial control (a) and the cavum septum pellucidum in an individual with antisocial personality disorder (b).

Coronal magnetic resonance image slices are at the level of the head of the anterior limb of the internal capsule, caudate, putamen, accumbens, and insula. Highlighted within the bue box is the septum pellucidum, dividing the lateral ventricles and bordered superiorly by the body of the corpus callosum and inferiorly by the fornix. The normal control (a) shows a fused septum pellucidum, whereas the participant with antisocial personality disorder (b) shows a fluid-filled cavum inside the two leaflets of the septum pellucidum.

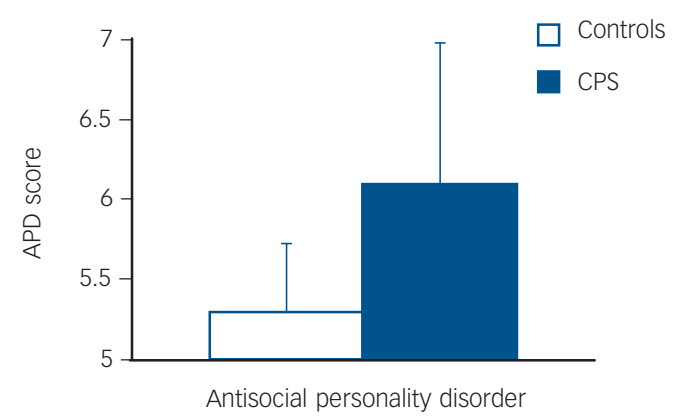

(b)

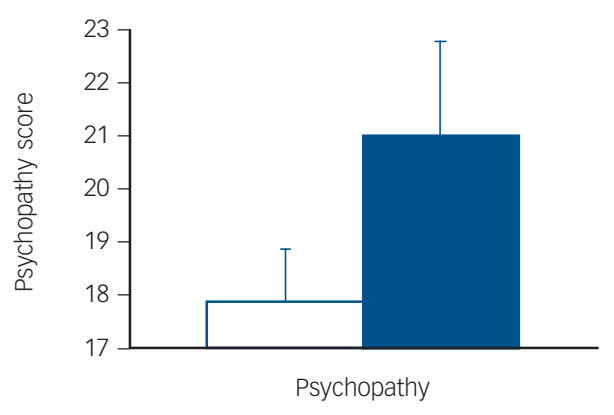

(c)

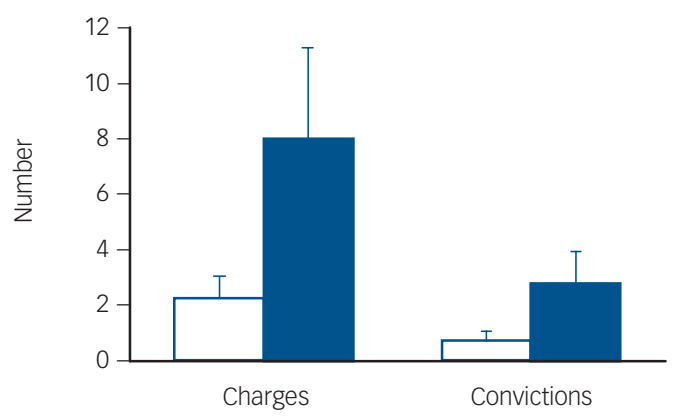

Fig. 2 Mean scores (with standard error bars) for those with a cavum septum pellucidum (CPS) and those without CSP (controls) on measures of antisocial personality disorder (a), psychopathy (b), and criminal charges or convictions (c). 
compared with controls, $F(1,80)=5.42, P=0.022, \eta^{2}=0.063$, with no CSP $\times$ gender interaction $(P=0.128)$. No such CSP main effect was observed for the deceptive-irresponsible factor, $F(1,80)=1.46$, $P=0.229$, and no CSP $\times$ gender interaction was observed $(P=0.22)$.

\section{Psychopathy}

A main effect of CSP grouping indicated higher psychopathy scores in the CSP group, $F(1,80)=8.21, P=0.005, \eta^{2}=0.093$ (Fig. 2). A significant CSP $\times$ gender interaction indicated particularly higher psychopathy scores in females with a CSP, $\left(F(1,80)=4.41, P=0.039, \eta^{2}=0.052\right.$.

\section{Subfactors of psychopathy}

A multivariate analysis of variance on the two main factors of psychopathy indicated a main effect of CSP group, $F(2,80)=4.47, \quad P=0.014, \quad \eta^{2}=0.10$, with no group $\times$ gender interaction $(P=0.10)$. Univariate analyses indicated higher scores in the CSP group on both the interpersonal/affective factor, $F(2,80)=4.98, P=0.028, \eta^{2}=0.06$, and the social deviance factor, $F(2,80)=8.82, P=0.004, \eta^{2}=0.10$ (Fig. 3).

\section{Criminal charges and convictions}

Those with a CSP present had more criminal charges and convictions than controls (Fig. 2). A multivariate analysis of variance indicated a main effect of CSP grouping on criminal charges and convictions, $F(2,83)=3.80, P=0.027, \eta^{2}=0.084$. with no group $\times$ gender interaction $(P=0.14)$. Univariate analyses indicated significant effects both for charges $(F(1,84)=7.32, P=0.008$, $\left.\eta^{2}=0.080\right)$ and convictions $\left(F(1,84)=6.00, P=0.016, \eta^{2}=0.067\right)$.

(a)

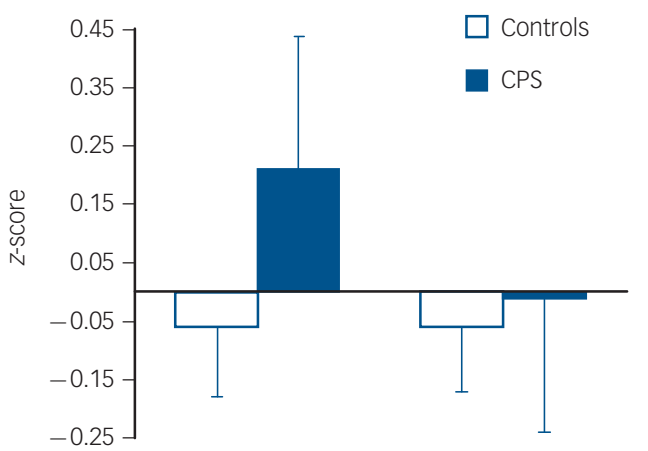

Aggressive/life-course Deceptive-irresponsible

(b)

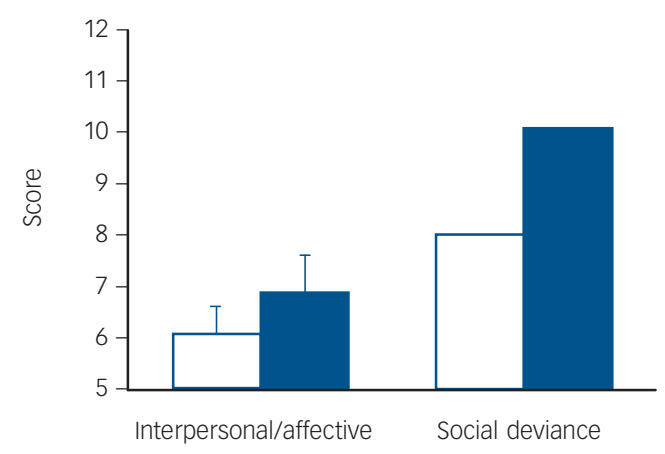

Fig. 3 Mean scores (z-transformed) and error bars on aggressive/life-course and deceptive-irresponsible subcomponents of antisocial personality disorder (a), and also interpersonal/affective and social deviance components of psychopathy (b) in groups with and without a cavum septum pellucidum (CPS)

\section{CSP in those lacking antisocial personality disorder but with some criminal offending}

Individuals who did not have a diagnosis of antisocial personality disorder, but who nevertheless had been either arrested or convicted for a crime showed more evidence of CSP. Individuals in the control group were divided into those with a criminal history of arrests/convictions, and those without such a criminal history. Participants without an antisocial personality disorder but with a history of arrests had a longer CSP than those participants without an antisocial personality disorder but without arrests, $F(1,61)=5.57, P=0.021, \eta^{2}=0.084$, with no main effect for gender $(P=0.94)$ or arrest $\times$ gender interaction $(P=0.60$, Fig. 4). Participants without an antisocial personality disorder but with a history of convictions showed a trend for a longer CSP than those participants without an antisocial personality disorder but without convictions, $F(1,61)=3.34, P=0.073, \eta^{2}=0.052$, with no main effect for gender $(P=0.61)$ or arrest $\times$ gender interaction $(P=0.94$, Fig. 4).

\section{Potential confounders}

Demographic, trauma and cognitive background data are provided in Table 1. The relationship between antisocial behaviour and CSP was independent of trauma exposure and head injury. With CSP as the grouping variable and dimensional antisocial measures as the dependent variables, main effects remained significant for antisocial personality disorder $(F(1,81)=4.89$, $\left.P=0.03, \eta^{2}=0.057\right)$, psychopathy $\left(F(1,78)=8.16, P=0.005 \eta^{2}=\right.$ $0.095)$, charges $\left(F(1,81)=5.71, P=0.019, \eta^{2}=0.066\right)$ and convictions $\left(F(1,81)=4.47, P=0.038, \eta^{2}=0.052\right)$ after simultaneously controlling for both post-traumatic stress and head injury.

We also tested the possibility that alcohol and substance dependence, schizophrenia-spectrum disorders (paranoid, schizoid, schizotypal personality), psychotic disorders (schizophrenia, schizoaffective, schizophreniform, delusional, brief psychotic episode, psychosis not otherwise specified) and mood disorders (bipolar, major depression) may be comorbid disorders accounting for the CSP-antisocial relationship. After simultaneously entry of all these covariates, the main effects of CSP remained significant for antisocial personality disorder $\left.F(2,70)=25.27, \quad P=0.001, \quad \eta^{2}=0.41\right), \quad$ psychopathy $(F(2,67)=$ 64.63, $\left.P=0.0001, \eta^{2}=0.659\right)$ and convictions $(F(2,70)=3.46$,

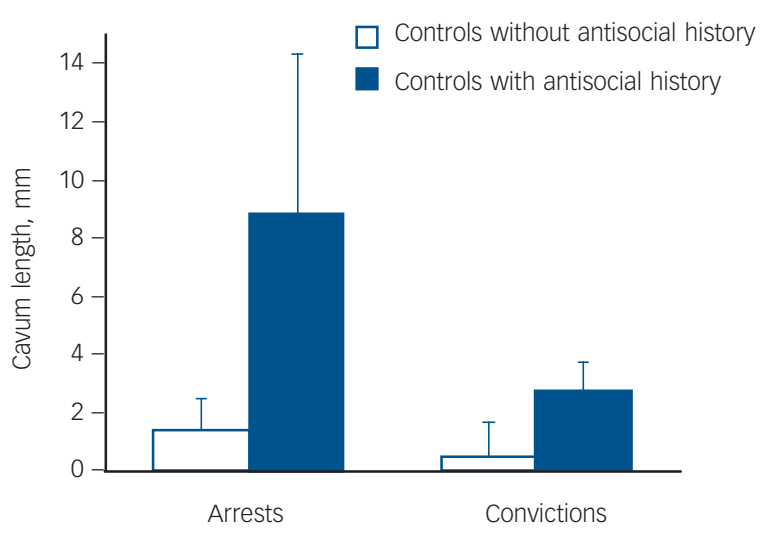

Fig. 4 Mean length ( $\mathrm{mm}$ ) of cavum septum pellucidum with standard error bars in controls lacking a diagnosis of antisocial personality disorder but who nevertheless have either been charged (a) or convicted (b) for criminal offences compared with controls lacking both antisocial personality disorder and charges/convictions. 
$\left.P=0.037, \eta^{2}=0.09\right)$, although the effect for charges was rendered marginally significant $\left(F(2,70)=2.44, P=0.094, \eta^{2}=0.065\right)$ being reduced in size by $25 \%$.

To further assess the possible influence of these factors, potential interaction effects between these confounds and CSP were tested for all antisocial dependent measures. No significant interactions were obtained $(P>0.075)$.

We also assessed whether age, education level, social class and total brain volume could confound relationships between CSP and antisocial variables. After entering these covariates simultaneously in a block, the main effect of CSP remained significant for antisocial personality disorder $\left(F(1,79)=4.65, P=0.034, \eta^{2}=0.056\right)$, psychopathy $\left(F(1,77)=4.147, \quad P=0.045, \quad \eta^{2}=0.051\right)$, charges $\left(F(1,80)=6.31, P=0.014 \eta^{2}=0.073\right)$ and convictions $(F(1,80)=$ $\left.12.37, P=0.001, \eta^{2}=0.134\right)$. Furthermore, there were no interactions between these variables and CSP in relation to the four antisocial measures $(P>0.138)$.

\section{Discussion}

\section{Main findings}

Individuals with a CSP have significantly higher levels of antisocial personality, psychopathy, criminal charges and convictions compared with those lacking a CSP. The pervasiveness of the association was further demonstrated by the same finding within the clinical control group; those lacking a diagnosis of antisocial personality disorder but who nevertheless were charged with a criminal offence showed a larger CSP than controls lacking both an antisocial personality disorder diagnosis and criminal charges. Findings could not be attributable to trauma exposure, head injury or comorbid psychiatric conditions. This convergence suggests that findings are relatively robust, and that a broad spectrum of antisocial behaviours ranging from psychopathy to antisocial personality disorder to criminal offending is associated with fundamental differences in degree of limbic neural maldevelopment. Findings appear to be the first to provide evidence for a neurodevelopmental brain abnormality in antisocial individuals, and support the hypothesis that early maldevelopment of limbic and septal structures predisposes to antisocial behaviours.

\section{Neurodevelopmental mechanisms}

In humans, impairment to the septum has long been hypothesised to result in psychopathic, antisocial and disinhibited behaviour. ${ }^{41}$ Because septal nuclei are contained in the septum pellucidum, morphological disruption to this structure would impair septal functioning and its regulatory connections to other limbic structures. In animals, the septum is critically involved in the regulation of aggression. ${ }^{42,43}$ Septal stimulation in a wide range of animals (rats, hamsters, mice, cats and monkeys) inhibits predatory aggression, ${ }^{44}$ whereas lesions to the septum result in increased aggression and disinhibited behaviour. ${ }^{44,45}$ In both highly aggressive mice and rats, reduced neural activation of the lateral septum as indicated by reduced c-fos expression results in disinhibition of the anterior hypothalamus and hypothalamic attack area, resulting in enhanced activation of parts of the periaqueductal grey area that in turn enhances attack behaviour. ${ }^{45}$ Of note, CSP was associated with aggressive features of antisocial personality disorder but not with non-aggressive features, indicating particular relevance of septal disruption to aggression in humans.

Neural maldevelopment of the septum is hypothesised to result in increased antisocial, aggressive and psychopathic behaviour through impaired bonding and attachment and a lack of prosocial affiliative behaviour in antisocial personality disorder, both of which have been linked to septal functioning. The lateral septal nuclei (an important oxytocin receptor-binding site) has been implicated in social attachment and bonding behaviours in animals. ${ }^{46}$ Antisocial psychopathic behaviour has been classically viewed as having its roots in early maternal deprivation during a critical period for bonding and attachment. ${ }^{47,48}$ Disruption to the septal system could consequently result in a failure to bond to caregivers (even in the absence of maternal deprivation) resulting in affectionless, psychopathic-like, antisocial behaviour. Furthermore, recent imaging research on prosocial behaviour in humans has demonstrated septal activation when making altruistic donations, with number of donations also significantly correlated with increased septal activation. ${ }^{49}$ The fact that CSP was related to the interpersonal/affective feature of psychopathy together with recent work showing that the emotional detachment factor of psychopathy is related to lack of both early maternal and paternal care ${ }^{50}$ gives rise to the hypothesis that psychopathy and life-course antisocial personality has a basis in neurodevelopmental abnormality in the limbic system.

The hypothesis that psychopathy and antisocial personality partly reflect fetal neural maldevelopment of the limbic system is not only consistent with cross-sectional findings from prior adult brain imaging studies of aggressive and violent individuals $s^{5,7,8,13}$ but is also broadly consistent with prospective longitudinal studies on babies, infants and young children showing that prenatal nicotine and alcohol exposure, ${ }^{51,52}$ prenatal malnutrition ${ }^{53}$ and early postnatal malnutrition ${ }^{54}$ are associated with long-term outcomes for antisocial and violent behaviour. All of these negative environmental events affect the developing brain, and some of these have been hypothesised to give rise to the midline limbic maldevelopment that in turn results in $\mathrm{CSP}^{28}$ These prior studies together with current findings suggest that factors affecting brain development during prenatal and very early postnatal periods may predispose to antisocial and aggressive behaviour. An advance that the current CSP findings add to prior imaging findings lies in the fact that because CSP is formed prior to the first 6 months of life, ${ }^{25}$ brain maldevelopment precedes the onset of criminal careers and is consequently hypothesised to be less likely a product of psychosocial and lifestyle influences that can be confounds in other adult imaging studies.

It is important to recognise that psychopathy, antisocial personality and criminal offending are not interchangeable conceptually, representing overlapping but distinct constructs. The fact that CSP is related to all of these antisocial constructs suggests a neurodevelopmental basis to a broad spectrum of antisocial behaviours that is shared by these overlapping constructs. This neurodevelopmental basis is not, however, shared with other externalising behaviour problems, including alcohol and substance misuse, because the CSP-psychopathy/antisocial relationship remained significant after controlling for these psychiatric confounds. Factors other than those reflected by CSP must inevitably give rise to the more distinguishing features of psychopathy, antisocial personality disorder and crime. A further caveat is that although CSP is known to be in place by 6 months of age, longitudinal research is required to further test the limbic neural maldevelopment hypothesis of this cross-sectional study. One recent prospective longitudinal study showing that poor fear conditioning (a marker for poor amygdala functioning) at age 3 years predicts crime at age 23 years suggest a neurodevelopmental contribution to crime causation. ${ }^{55}$ Finally, although one analysis indicated a group $\times$ gender interaction indicating that CSP was particularly associated with psychopathy in females, this interaction must be treated with caution because no such interaction 
was observed for either psychopathy subfactors or for any other antisocial measure.

\section{Clinical implications}

In conclusion, the association between cavum septum pellucidum and the spectrum of antisocial behaviours supports a neurodevelopmental hypothesis of antisocial personality disorder and psychopathy. If serious offending is in part neurodevelopmentally determined, successful prevention efforts would be most effective if they began prenatally. One such biosocial prenatal programme that targeted maternal health factors resulted in significant reductions in juvenile delinquency 15 years later. ${ }^{56}$ This programme, which aimed to reduce smoking and alcohol use during pregnancy, might have protected against CSP and associated limbic maldevelopment because prenatal alcohol use is associated with $\mathrm{CSP}^{28}$ Similarly, one experimental intervention that enhanced the early environment of young children from ages 3-5 years with better nutrition, more physical exercise and cognitive stimulation has been shown to both improve brain functioning at age $11^{57}$ and reduce criminal offending at age 23 years by $34 \% .^{58}$ Such preschool programmes would not be expected to reduce the earlier development of CSP but would be expected to ameliorate limbic maldevelopment because physical exercise is known to promote neurogenesis in the dentate gyrus of the hippocampus. ${ }^{59}$ Clinical, social and educational services that improve prenatal and perinatal health in underserved at-risk mothers may conceivably prevent limbic neurodevelopment, reduce antisocial personality disorder and violence, and partially alleviate this major public health problem. Finally, because it has been argued that CSP is a heritable contribution ${ }^{40}$ and because approximately $50 \%$ of the variance in adult antisocial behaviour is heritable ${ }^{60}$ (with higher heritability in children with callousunemotional traits), ${ }^{61}$ genetic influences on limbic maldevelopment in antisocial personality and psychopathy must also be considered alongside environmental influences.

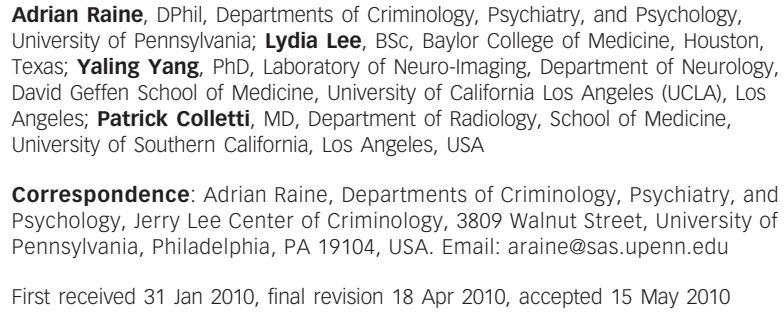

\section{Funding}

This study was supported by an Independent Scientist Award (K02 MH01114-01) and grants from the National Institute of Mental Health (5 RO3 MH50940-02) and the Wacker Foundation to A. R.

\section{Acknowledgements}

The authors wish to thank Jennifer Bobier, Nicole Diamond, Kevin Ho, Lori Lacasse, Todd Lencz, Shari Mills and Pauline Yaralian for assistance in data collection.

\section{References}

1 Shepherd J. Combined approach is needed - violence as a public health problem. BMJ 2003; 326: 104.

2 Department of Health and Human Services. Youth Violence: A Report of the Surgeon General. Department of Health and Human Services, 2001.

3 Moffitt TE. Adolescence-limited and life-course-persistent antisocial behavior: a developmental taxonomy. Psychol Rev 1993; 100: 674-701.
4 Raine A, Lencz T, Scerbo A. Antisocial personality: neuroimaging, neuropsychology, neurochemistry, and psychophysiology. In Neuropsychiatry of Behavior Disorders (ed JH Ratey): 50-78. Blackwell, 1995.

5 Davidson RJ, Putnam KM, Larson CL. Dysfunction in the neural circuitry of emotion regulation - a possible prelude to violence. Science 2000; 289 : 591-4.

6 Blair RJR. The amygdala and ventromedial prefrontal cortex: functional contributions and dysfunction in psychopathy. Philos Trans $R$ Soc B Bio Sci 2008; 363: 2557-65

7 Kiehl KA. A cognitive neuroscience perspective on psychopathy: evidence for paralimbic system dysfunction. Psychiatry Res 2006; 142: 107-28.

8 Raine A, Buchsbaum M, LaCasse L. Brain abnormalities in murderers indicated by positron emission tomography. Biol Psychiatry 1997; 42: 495-508.

9 Laakso MP, Vaurio O, Savolainen $\mathrm{L}$, Repo $\mathrm{E}$, Soininen $\mathrm{H}$, Aronen $\mathrm{HJ}$, et al. A volumetric MRI study of the hippocampus in type 1 and 2 alcoholism. Behav Brain Res 2000; 109: 177-86.

10 Raine A, Ishikawa SS, Arce E, Lencz T, Knuth KH, Bihrle S, et al. Hippocampal structural asymmetry in unsuccessful psychopaths. Biol Psychiatry 2004; 55: 185-91.

11 George DT, Rawlings RR, Williams WA, Phillips MJ, Fong G, Kerich M, et al. A select group of perpetrators of domestic violence: evidence of decreased metabolism in the right hypothalamus and reduced relationships between cortical/subcortical brain structures in position emission tomography. Psychiatry Res Neuroimaging 2004; 130: 11-25.

12 Raine A, Yang Y. Neural foundations to moral reasoning and antisocial behavior. Soc Cogn Affect Neurosci 2006; 1: 203-13.

13 Oliveira-Souza R, Hare RD, Bramati IE, Garrido GJ, Ignacio FA, Tovar-Moll F, et al. Psychopathy as a disorder of the moral brain: fronto-temporo-limbic grey matter reductions demonstrated by voxel-based morphometry. Neuroimage 2008; 40: 1202-13.

14 Raine A, Stoddard J, Bihrle S, Buchsbaum M. Prefrontal glucose deficits in murderers lacking psychosocial deprivation. Neuropsychiatry Neuropsychol Behav Neurol 1998; 11: 1-7.

15 Bechara A, Damasio H, Tranel D, Damasio AR. Deciding advantageously before knowing the advantageous strategy. Science 1997; 275: 1293-4.

16 Damasio AR. A neural basis for sociopathy. Arch Gen Psychiatry 2000; 57 $128-9$.

17 Damasio A. Descartes' Error: Emotion, Reason, and the Human Brain. GP Putnam's Sons, 1994.

18 Viding E, Jones AP. Cognition to genes via the brain in the study of conduct disorder. Q J Exp Psychol 2008; 61: 171-81.

19 Sterzer P, Stadler C, Poustka F, Kleinschmidt A. A structural neural deficit in adolescents with conduct disorder and its association with lack of empathy. Neurolmage 2007; 37: 335-42.

20 Marsh AA, Finger EC, Mitchell DGV, Reid ME, Sims C, Kosson DS, et al. Reduced amygdala response to fearful expressions in children and adolescents with callous-unemotional traits and disruptive behavior disorders. Am J Psychiatry 2008; 165: 712-20

21 Mechelli A, Tognin S, McGuire PK, Prata D, Sartori G, Fusar-Poli P, et al. Genetic vulnerability to affective psychopathology in childhood: a combined voxel-based morphometry and functional magnetic resonance imaging study. Biol Psychiatry 2009; 66: 231-7.

22 De Brito SA, Mechelli A, Wilke M, Laurens KR, Jones AP, Barker GJ, et al. Size matters: increased grey matter in boys with conduct problems and callous-unemotional traits. Brain 2009; 132: 843-52.

23 Jones AP, Laurens KR, Herba CM, Barker GJ, Viding E. Amygdala hypoactivity to fearful faces in boys with conduct problems and callous-unemotional traits. Am J Psychiatry 2009; 166: 95-102.

24 Pansky B, Allen DJ, Budd GC. Review of Neuroscience (2nd edn). Macmillan Publishing Company, 1988.

25 Sarwar M. The septum pellucidum - normal and abnormal. Am J Neuroradiol 1989; 10: 989-1005.

26 Kim MJ, Lyoo IK, Dager SR, Friedman SD, Chey J, Hwang J, et al. The occurrence of cavum septi pellucidi enlargement is increased in bipolar disorder patients. Bipolar Disord 2007; 9: 274-80.

27 Nopoulos P, Krie A, Andreasen NC. Enlarged cavum septi pellucidi in patients with schizophrenia: clinical and cognitive correlates. I Neuropsychiatry Clin Neurosci 2000; 12: 344-9.

28 Swayze VW, Johnson VP, Hanson JW, Piven J, Sato Y, Giedd JN, et al. Magnetic resonance imaging of brain anomalies in fetal alcohol syndrome. Pediatrics 2006; 99: 232-40.

29 Raine A, Lencz T, Bihrle S, LaCasse L, Colletti P. Reduced prefrontal gray matter volume and reduced autonomic activity in antisocial personality disorder. Arch Gen Psychiatry 2000; 57: 119-27. 
30 Ventura J, Liberman RP, Green MF, Shaner A, Mintz J. Training and quality assurance with Structured Clinical Interview for DSM-IV (SCID-I/P). Psychiat Res 1998; 79: 163-73.

31 American Psychiatric Association. Diagnostic and Statistical Manual of Mental Disorder (4th edn) (DSM-IV). APA, 1994.

32 First MB, Spitzer RL, Gibbon M, Williams JBW, Benjamin L. Structured Clinical Interview for DSM-IV Axis II Personality Disorders (SCID-II, Version 2.0). New York State Psychiatric Institute, 1994.

33 Hare RD. The Hare Psychopathy Checklist-Revised (PCL-R) (2nd edn). MultiHealth Systems, 2003.

34 Raine A, Lencz T, Taylor K, Hellige JB, Bihrle S, LaCasse L, et al. Corpus callosum abnormalities in psychopathic antisocial individuals. Arch Gen Psychiatry 2003; 60: 1142.

35 Yang YL, Raine A, Lencz T, Bihrle S, LaCasse L, Colletti P. Volume reduction in prefrontal gray matter in unsuccessful criminal psychopaths. Biol Psychiatry 2005; 57: 1103-8.

36 Wechsler D. Wechsler Adult Intelligence Scale - Revised. Psychological Corporation, 1981.

37 Hollingshead AB. Four Factor Index of Social Status. Yale University, 1975.

38 Rex DE, Ma JQ, Toga AW. The loni pipeline processing environment. Neuroimage 2003; 19: 1033-48.

39 Kwon JS, Shenton ME, Hirayasu Y, Salisbury DF, Fischer IA, Dickey CC, et al. MRI study of cavum septi pellucidi in schizophrenia, affective disorder, and schizotypal personality disorder. Am J Psychiatry 1998; 155: 509-15.

40 May FS, Chen QC, Gilbertson MW, Shenton ME, Pitman RK. Cavum septum pellucidum in monozygotic twins discordant for combat exposure: relationship to posttraumatic stress disorder. Biol Psychiatry 2004; 55 : 656-8.

41 Gorenstein EE, Newman JP. Disinhibitory psychopathy - a new perspective and a model for research. Psychol Rev 1980; 87: 301-15.

42 Potegal M, Blau A, Glusman M. Effects of anteroventral septal lesions on intraspecific aggression in male hamsters. Physiol Behav 1981; 26: 407-12.

43 Siegel A, Bhatt S, Bhatt R, Zalcman SS. The neurobiological bases for development of pharmacological treatments of aggressive disorders. Curr Neuropharmacol 2007; 5: 135-47.

44 Clemete $\mathrm{CD}$, Chase $\mathrm{MH}$. Neurobiological substrates of aggressive behavior. Annu Rev Physiol 1973; 35: 329-56.

45 Veenema $\mathrm{AH}$, Neumann ID. Neurobiological mechanisms of aggression and stress coping: a comparative study in mouse and rat selection lines. Brain Behav Evol 2007; 70: 274-85

46 Insel TR, Young $\amalg$. The neurobiology of attachment. Nat Rev Neurosci 2001; 2: $129-36$

47 Bowlby J. Attachment and Loss: I. Attachment. Hogarth Press, 1969.
48 Rutter M. Maternal Deprivation Reassessed (2nd edn). Penguin, 1982.

49 Moll J, Krueger F, Zahn R, Pardini M, Oliveira-Souzat R, Grafman J. Human fronto-mesolimbic networks guide decisions about charitable donation. Proc Natl Acad Sci USA 2006; 103: 15623-8.

50 Gao $\mathrm{Y}$, Raine A, Chan $\mathrm{F}$, Venables $\mathrm{PH}$, Mednick SA. Early maternal and paternal bonding, childhood physical abuse, and adult psychopathic personality. Psychol Med 2010; 40: 1007-16.

51 Brennan PA, Grekin ER, Mednick SA. Maternal smoking during pregnancy and adult male criminal outcomes. Arch Gen Psychiatry 1999; 56: 215-9.

52 Streissguth AP, Bookstein FL, Barr HM, Sampson PD, O'Malley K, Young JK. Risk factors for adverse life outcomes in fetal alcohol syndrome and fetal alcohol effects. J Dev Behav Pediatr 2004; 25: 228-38.

53 Neugebauer R, Hoek HW, Susser E. Prenatal exposure to wartime famine and development of antisocial personality disorder in early adulthood. JAMA 1999; 282: 455-62.

54 Liu JH, Raine A, Venables PH, Dalais C, Mednick SA. Malnutrition at age 3 years and externalizing behavior problems at ages 8,11 and 17 years. Am J Psychiatry 2004; 161: 2005-13.

55 Gao Y, Raine A, Venables PH, Mednick SA. Poor fear conditioning at age 3 years predisposes to adult crime at age 23. Am J Psychiatry 2010; 167: 15660

56 Olds D, Henderson CRJ, Cole R, Eckenrode J, Kitzman H, Luckey D, et al. Long-term effects of nurse home visitation on children's criminal and antisocial behavior: 15-year follow-up of a randomized controlled trial. JAMA 1998; 280: 1238-44.

57 Raine A, Venables PH, Dalais C, Mellingen K, Reynolds C, Mednick SA. Early educational and health enrichment at age 3-5 years is associated with increased autonomic and central nervous system arousal and orienting at age 11 years: evidence from the Mauritius Child Health Project. Psychophysiol 2001; 38: 254-66.

58 Raine A, Mellingen $\mathrm{K}$, Liu JH, Venables PH, Mednick SA. Effects of environmental enrichment at 3-5 years on schizotypal personality and antisocial behavior at ages 17 and 23 years. Am J Psychiatry 2003; 160 1627-35.

59 van Praag H, Kempermann G, Gage FH. Running increases cell proliferation and neurogenesis in the adult mouse dentate gyrus. Nat Neurosci 1999; 2 : 266-70.

60 Moffitt TE. The new look of behavioral genetics in developmental psychopathology: gene-environment interplay in antisocial behaviors. Psychol Bull 2005; 131: 533-54.

61 Viding $E$, Jones AP, Frick PJ, Moffitt TE, Plomin R. Heritability of antisocial behaviour at 9: do callous-unemotional traits matter? Dev Sci 2008; 11: $17-22$. 